\title{
Stress 3Ps and the Health Conditions of Lecturers in Tertiary Institution in Nigeria
}

\author{
Victoria Agunanne'), Annabel Obinna-Akakuru $^{2)}$, Olachi Oparanozie ${ }^{3)}$, Jacinta Achonu ${ }^{4)}$ \\ 1) Department of Life Science Education, Faculty of Education, Imo State University Owerri, Nigeria \\ 2) Department of Psychology, G\&C, Alvan Ikoku Federal College of Education, Owerri, Nigeria \\ 3) Department of Educational Sociology, Imo State University, Owerri, Nigeria \\ 4) Public Relations Office, Federal Medical Centre, Owerri, Nigeria
}

Email: anniemagma@gmail.com ${ }^{2}$

\begin{abstract}
This study examined stress 3Ps (Physical, Psychological and Psycho-Social) as factors on health conditions of lecturers in Imo State. Nigeria. Three specific purposes, three research questions and three hypotheses guided the work. The study employed inferential survey research design. The population of this study consisted of all lecturers in the tertiary institutions in Imo state which are eight thousand, three hundred $(8,300)$. The sample size for this is 382, determined using Taro Yamane formula. The researcher applied random sampling technique to ensure that all selected groups have an equal chance with the other sample that is not selected. The instrument for data collection is a structured questionnaire tagged "Stress 3Ps as factors on health conditions of Lecturers". The validity of the research instrument was determined by two specialists in Health Education and one specialist in Educational Measurement and Evaluation, from Alvan Ikoku FCE Owerri and Imo State University Owerri, respectively, while the reliability coefficient over time of the instrument for data collection was established through test retest method of Pearson product moment correlation coefficient (PPMCC) statistics which gave a reliability coefficient of 0.94. The research questions were answered using, mean, and standard deviations presented in tables, while the hypotheses was tested using t-test statistics at 0.05 level of significance. Findings in the course of this study indicated that lecturers exposed to hectic academic activity will experience stress; physical stress affects the mental state of lecturers reducing their level of productivity; psychological stress limits the emotional stability of lectures and directly affects their health condition; psychosocial stress interferes in the intrapersonal and interpersonal relationship of lectures leading to withdrawal and health instability. This study therefore recommends that seminars, workshops and conferences on occupational health services, should be organized periodically for lecturers so as to improve their knowledge on occupational stress and related issues. Also, Lecturers should be encouraged to participate in sport, exercise and fitness programmes in other to maintain a good health status.
\end{abstract}

Keywords: stress, health condition, lecturers, tertiary institution

\section{Introduction}

Health condition is defined as the totality of the health status of an individual at a given time, in relation to blood pressure, body mass index (BMI), waist-hip ratio (WHR) and random blood sugar (RBS). These health condition parameters were used to assess cardiometabolic disorders which include disorders in glucose regulation, central obesity, dyslipidaemia and hypertension (Ali, Jaacks, Kowalski, Siegel and Ezzati, 2015). These cardiometabolic disorders are risk factors for the development of noncommunicable diseases (NCDs) such as cardiovascular diseases and diabetes. The burden of noncommunicable diseases is well documented in lowand middle-income countries (LMICs) (Ekwunife \& Aguwa, 2011). Eighty per cent of premature deaths associated with NCDs occur in LMICs, and they usually affect ages between 30 and 69 years. Statistics show that there is an increase in global deaths associated with NCDs annually. 
In 2018, 60.3\% deaths of lecturers annually were attributed to Cardiovascular dxiseases (CVDs) alone having a global annual death rate of 17.7 million $(44.3 \%)$ and the figure for diabetes mellitus is about $4.0 \%$ (Allender, Wickramasinghe, Goldacre, Matthews \& Katulanda, 2011). Hypertension, diabetes mellitus and obesity share some characteristics in relation to diagnosis, management, and prevention. Waist-hip ratio (WHR) is an indicator that complements BMI measurement to identify individuals at risk of obesity-related morbidity (WHO, 2008). Overweight, obesity and WHR are associated with increased risk for development of diabetes, hypertension and ischemic heart diseases (Isara \& Okundia, 2015). BMI is significantly associated with manifestation of angina, myocardial infarction, heart failure and sudden death in both males and females (Ekwunife \& Aguwa, 2011).

Hypertension, diabetes and hyperlipidaemia are linked with coronary heart disease that have high mortality and morbidity globally. Hence they are of public health concern globally. One in three adults globally have raised blood pressure which is the cause of about $50 \%$ of all deaths from stroke and other heart diseases one in 10 adults have diabetes mellitus and one in four women are overweight (Joseph-Shehu, Irinoye, \& Ajani, 2016).

High blood pressure is a risk factor for stroke, ischaemic heart diseases, heart failure and chronic kidney diseases. Commonly referred to as the silent killer, it is liable to remain untreated since most people are not aware of the symptoms or warning signs. Untreated hypertension may lead to coronary heart diseases or congestive heart failure, which account for $50 \%$ of all deaths associated with hypertension; $33 \%$ of untreated hypertension may lead to stroke, and $10-15 \%$ will result in renal failures(Allender et al., 2011; Ekwunife \& Aguwa, 2011; Isara \& Okundia, 2015).

It has also been observed that there has been an increase in the rate of cardiovascular diseases amongst lecturers in Nigeria. According to the Nigerian Medical Association, 76\% of academic staff in higher institutions suffer from cardiovascular and other health related issues yearly. Bassey \& Otu, (2021) reports that an astonishing 13.4 million working days was found to be lost to stress-related illness, depression, or anxiety every year. The effects of stress are not borne by stressed individuals alone but rather they spill over to affect the performance of the organizations where these individuals earn their living. Despite these findings, there exist little or no literature to the best of the researcher's knowledge, on stress as a factor on the job performance and health condition of lecturers in Imo State using the variables employed in this study. Very little is still known about the factors that significantly impact on the stress of lecturers in tertiary institutions in Imo State. It is against this backdrop that the researcher wonders if stress is a factor on the job performance and health condition of lecturers in tertiary institutions in Imo State, Nigeria?

\subsection{Purpose of the Study}

The purpose of the study was to examine stress as a factor on job performance and health conditions of lecturers in Imo State. Specifically, the purpose of the study was to:

1. assess the impact of physical stress on the health conditions of lecturers in the tertiary institutions in Imo State;

2. assess the impact of psychological stress on the health conditions of lecturers in the tertiary institutions in Imo State; and

3. assess the impact of psycho-social stress on the health conditions of lecturers in the tertiary institutions in Imo State. 


\subsection{Research Questions}

The following research questions guided this study:

1. How is physical stress a factor on the health conditions of lecturers in the tertiary institutions in Imo State?

2. To what extent is psychological stress a factor on the health conditions of lecturers in the tertiary institutions in Imo State?

3. How is psycho-social stress a factor on the health conditions of lecturers in the tertiary institutions in Imo State?

\section{Literature Review}

Stress, according to Slyers (2011) means a general response which the human body makes to any demand on it. It is a worry which is physical, psychological, physiological and sociological which may result from not meeting with certain demands at the work place. Oboegbulem (2007) sees stress as a process in which environmental events or forces, called stressors, threaten an organism's existence and well-being, and how the individual responds to such threat. It could also be seen as a feeling which occurs when an individual's working or living conditions or circumstances make demands beyond the individual's capacity to handle such situation physically or emotionally.

In consonance with foregoing, Uko (2012) stated that stress is also a condition of being subject to external forces or pressures which can either be good (eustress) or bad (distress). Eustress represents moderate and low stress levels and distress is frequently defined as high stress level. Principals and teachers who experience eustress will be able to meet job demands and this may engender positive work life (e.g. satisfaction and positive moral values), while principals and teachers who experience distress will not be able to fulfill job demands leading to dissatisfaction which affects an individual's productivity, effectiveness, personal health and quality of work (Leka, Griffiths \& Cox, 2013).

In another view, Kyriacon (2001) posits job stress as the experience of negative emotional states such as frustration, worry, anxiety and depression. Buttressing this point, Reddy \& Anuradha (2013) stated that job stress as an employee's mental state aroused by a job situation or a combination of situations perceived as presenting excessive and divergent demands. It occurs when there is a discrepancy between the demands of the work and individual's ability to carry out and complete these demands (Mahmood, Nudrat \& Zahoor, 2013). Occupational stress, conceptualized in this study as such problem like work overload, pressure from parents and problems in curriculum implementation, lack of autonomy in execution of responsibilities, conflict between work and family responsibilities, poor academic performance of students, students indiscipline and poor working environment constitute occupational stressors. Ofuegbu \& Nwadianni (2006) posit that Stress factors broadly fall into four types or categories: physical stress, psychological stress, psychosocial stress, and psychospiritual stress; these stresses affect the job performance of lecturers

\section{Hypotheses}

The following hypotheses were formulated to guide the study and tested at 0.05 level of significance:

Ho1 Physical stress as a factor on the health conditions of lecturers in the tertiary institutions in Imo State is not greater than the expected mean of 12.5. 
$\mathrm{Ho}_{2}$ Psychological stress as a factor on the health conditions of lecturers in the tertiary institutions in Imo State is not greater than the expected mean of 12.5.

Ho3 Psycho-social stress as a factor on the health conditions of lecturers in the tertiary institutions in Imo State is not greater than the expected mean of 12.5.

\section{Research Method}

The study employed inferential survey research design. The survey research is one in which a group of people or items is studied by collecting and analyzing data from few people or items considered to be representative of the entire group. In other words, only a part of the population is studied, and findings from this are expected to be generalized to the entire population. The population of this study consisted of all lecturers in the tertiary institutions in Imo state; Imo State University Owerri, Federal University of Technology, Alvan Ikoku Federal College of Education, Owerri, Federal College of Land Resources Technology Oforola, Imo State Polytechnics Umuagwo, Federal Polytechnics Nekede, Imo State College of Education, Ihette Uboma and ICCN Institute of finance and investment Nkwere. The population is eight thousand, three hundred $(8,300)$. The sample size is 382 , this was determined using Taro Yamane formula (Yamane, 1973), from the population. For the effective study, a simple random sampling procedure was adopted on the institutions to be visited, since it would allow for equiprobability to all members of the institutions. The researcher applied random sampling technique to ensure that all selected groups have an equal chance with the other sample that is not selected. The instrument for data collection is a structured questionnaire tagged "Stress 3Ps as factor on health condition of Lecturers". It is made up of two sections i.e. A and B. Section A of the instrument requests for demographic information, Section B - G, focused on stressors and the options are "Strongly Agreed (4-point);", "Agreed (3-point);", "Disagreed (2-point);" and "Strongly Disagreed (1-point)".

Copies of the instruments, together with the purpose of the study and research questions were sent to two specialists in Health Education and one specialists In Educational Measurement and Evaluation, from Alvan Ikoku FCE Owerri and Imo State University Owerri, respectively, for vetting. They vetted the instrument in terms of content validity, face validity, simplicity and clarity of vocabulary, sentence structure, appropriateness and relevance of the instrument to the purpose of the study. The instrument was used based on the corrections effected and comments made by these specialties. This ensured face and content validity of the instrument. The Reliability coefficient over time of the instrument for data collection was established through test retest method. The researcher administered copies of the instrument on 15 respondents from Hezekiah University Lecturers, Umudi. The researcher used Hezekiah University Lecturers, Umudi, a private university which was not part of the research. After an interval of two weeks, the same respondents were re-administered with the same instrument which was reshuffled. Each respondent obtained two sets of scores $\mathrm{X}$ and $\mathrm{Y}$ for the test and retest scores respectively. The data obtained from the two administrations of the instrument was analysed using Pearson product moment correlation coefficient (PPMCC) statistics which gave a reliability coefficient of 0.94. In order to ensure proper administration of these instruments, the researcher made several personal visits to the tertiary institutions, with the help of research assistants, who were trained by the researcher. At each visit, with the help of the research assistants, the researcher administered the instrument face to face. This method was used to ensure clarification of questions, words and phrases that needed to be clarified. This afforded the researcher the opportunity to recover all the copies of the instrument. The data gathered was analyzed using mean, and standard deviations presented in tables. t-test statistics was used to test the 
hypotheses at 0.05 level of significance.

\section{Findings and Discussions}

Research Question One: How is physical stress a factor on the health conditions of lecturers in the tertiary institutions in Imo State?

Table 1: How Physical Stress is a Factor on the Health Conditions of Lecturers in the Tertiary Institutions in Imo State?

\begin{tabular}{lllll}
\hline S/N & $\begin{array}{l}\text { Items } \\
\text { Whenever I am stressed, I experience the following } \\
\text { symptoms }\end{array}$ & Mean & SD & Remark \\
\hline 1. & Inability to concentrate & 2.92 & 0.81 & Accepted \\
2. & Sleeping too much or too little & 2.67 & 0.95 & Accepted \\
3. $\quad$ Diarrhea or constipation & 2.92 & 0.97 & Accepted \\
4. $\quad$ Changes in blood glucose, Nausea, dizziness & 2.87 & 0.92 & Accepted \\
5. Chest pain, rapid heartbeat & 2.95 & 0.92 & Accepted \\
& Grand Mean & $\mathbf{1 4 . 3 3}$ & & \\
\hline
\end{tabular}

Table 1 indicates that Inability to concentrate, Sleeping too much or too little, Diarrhea or constipation, Changes in blood glucose, Nausea, dizziness, Chest pain, rapid heartbeat, physical stress, are the ways which physical stress affects the health condition of lecturers in tertiary institutions in Imo State as their mean scores were more than 2.5 which is the criterion mean.

Hypotheses 1: Physical stress as a factor on the health conditions of lecturers in the tertiary institutions in Imo State is not greater than the expected mean of 12.5.

Table 2. One Way Sample t-Test Showing Physical Stress as a Factor on Health Conditions of Lecturers in the Tertiary Institutions in Imo State.

\begin{tabular}{|c|c|c|c|c|c|c|c|}
\hline & \multicolumn{7}{|c|}{ Test Value $=12.5$} \\
\hline & \multirow[b]{2}{*}{$\mathrm{T}$} & \multirow[b]{2}{*}{ Mean } & \multirow[b]{2}{*}{ Df } & \multirow[b]{2}{*}{ Sig. (2-tailed) } & \multirow{2}{*}{$\begin{array}{l}\text { Mean } \\
\text { Difference }\end{array}$} & \multicolumn{2}{|c|}{$\begin{array}{ll}95 \% & \text { Confidence } \\
\text { Interval of the } \\
\text { Difference }\end{array}$} \\
\hline & & & & & & Lower & Upper \\
\hline Physical stress & 13.593 & 14.33 & 381 & .000 & 1.82723 & 1.5629 & 2.0915 \\
\hline
\end{tabular}

Table 2 shows that the significance of $t$ value is .000 which is less than 0.05 and the mean is 14.33 which is greater than the test value which is 12.5 , therefore we reject the hypothesis, indicating that physical stress is a factor on health conditions of lecturers in tertiary institutions in Imo State. 
This study revealed that physical stress is a factor on the health conditions of lecturers in the tertiary institutions. The study also revealed that Inability to concentrate, Sleeping too much or too little, Diarrhea or constipation, Changes in blood glucose, Nausea, dizziness, Chest pain, rapid heartbeat, physical stress, are the ways which physical stress affects the health condition of lecturers in tertiary institutions in Imo State. This result is in line with the findings of Ahsan, Abdullah, YongGunfle \& Alam (2009), who studied the determinants of job stress; management role, relationship with others, work load pressure, homework interface, role ambiguity and performance pressure. The finding of the study showed that, there is a significant relationship between job stress, job satisfaction and the health of workers.

Research Question Two: To what extent is psychological stress a factor on the health conditions of lecturers in the tertiary institutions in Imo State?

Table 3. To What Extent is Psychological Stress a Factor on the Health Conditions of Lecturers in the Tertiary Institutions in Imo State?

\begin{tabular}{lllll}
\hline S/N & \multicolumn{1}{c}{ Items } & & & \\
& $\begin{array}{l}\text { Whenever I Am Stressed, I Experience the Following } \\
\text { Symptoms }\end{array}$ & Mean & SD & Remark \\
\hline 1. & Using alcohol, cigarettes, or drugs to relax & 3.12 & 0.92 & Accepted \\
2. Pessimistic approach or thoughts & 3.93 & 0.99 & Accepted \\
3. Anxious or racing thoughts & 3.31 & 0.76 & Accepted \\
4. Constant worrying & 3.76 & 0.86 & Accepted \\
5. Nervous habits (e.g. nail biting, pacing) & 3.54 & 0.91 & Accepted \\
& Grand Mean & $\mathbf{1 7 . 6 6}$ & &
\end{tabular}

Table 3 indicates that using alcohol, cigarettes, or drugs to relax, pessimistic approach or thoughts, anxious or racing thoughts, constant worrying, and nervous habits (e.g. nail biting, pacing) are the extent which of psychological stress affects the health condition of lecturers in tertiary institutions in Imo State as their mean scores were more than 2.5 which is the criterion mean.

Hypotheses 2: Psychological stress as a factor on the health conditions of lecturers in the tertiary institutions in Imo State is not greater than the expected mean of 12.5.

Table 4. One Way Sample t-Test Showing Psychological Stress as a Factor on Health Conditions of Lecturers in the Tertiary Institutions in Imo State.

\begin{tabular}{|c|c|c|c|c|c|}
\hline \multirow{2}{*}{} & \multicolumn{5}{|c|}{ Test Value $=12.5$} \\
\cline { 2 - 6 } & $\mathrm{T}$ & Df & $\begin{array}{c}\text { Sig. (2- } \\
\text { tailed) }\end{array}$ & $\begin{array}{c}\text { Mean } \\
\text { Difference }\end{array}$ & $\begin{array}{c}\text { 95\% Confidence } \\
\text { Interval of the } \\
\text { Difference }\end{array}$ \\
\hline
\end{tabular}




\begin{tabular}{|l|c|c|c|c|c|c|c|}
\hline & & Mean & & & & Lower & Upper \\
\hline $\begin{array}{l}\text { Psychological } \\
\text { stress }\end{array}$ & 80.709 & 17.66 & 381 & .000 & 5.16230 & 5.0365 & 5.2881 \\
\hline
\end{tabular}

Table 4 shows that the significance of $t$ value is .000 which is less than 0.05 and the mean is 17.66 which is greater than the test value which is 12.5 , therefore we reject the hypothesis indicating that psychological stress is a factor on health conditions of lecturers in tertiary institutions in Imo State.

It was revealed in this study that psychological stress is a factor on the health conditions of lecturers in the tertiary institutions. This result is so as using alcohol, cigarettes, or drugs to relax, pessimistic approach or thoughts, anxious or racing thoughts, constant worrying, and nervous habits (e.g. nail biting, pacing) were identified as the extent which psychological stress affects the health condition of lecturers in tertiary institutions in Imo State. This result is in line with the findings of Tahir (2011), who investigated the effectiveness of teaching stress on academic performance of college teachers in Pakistan. The study revealed that intrinsic and extrinsic variables have positive effect on academic performance and health of college teachers. The study also showed that significant difference was found between academic performance of teachers of public and private colleges.

Research Question Three: How is psycho-social stress a factor on the health conditions of lecturers in the tertiary institutions in Imo State?

Table 5. The Extent to Which Psycho-Social Stress is a Factor on the Health Conditions of Lecturers in the Tertiary Institutions in Imo State.

\begin{tabular}{lllll}
\hline S/N & $\begin{array}{l}\text { Items } \\
\text { Whenever I am stressed, I experience the following } \\
\text { symptoms }\end{array}$ & Mean & SD & Remark \\
\hline 1. & Depression & 3.11 & 0.93 & Accepted \\
2. Withdrawal & 2.98 & 0.93 & Accepted \\
3. $\quad$ Isolating oneself from others & 3.36 & 0.76 & Accepted \\
4. $\quad$ Procrastinating or neglecting responsibilities & 3.84 & 0.85 & Accepted \\
5. $\quad$ Loss of sex drive & 3.71 & 0.78 & Accepted \\
& Grand Mean & $\mathbf{1 7 . 0}$ & & \\
\hline
\end{tabular}

Table 5 indicates that depression, withdrawal, isolating oneself from others, procrastinating or neglecting responsibilities, loss of sex drive are the extent which psycho-social stress affects the health condition of lecturers in tertiary institutions in Imo State as their mean scores were more than 2.5 which is the criterion mean.

Hypotheses 3. Psycho-social stress as a factor on the health conditions of lecturers in the tertiary institutions in Imo State is not greater than the expected mean of 12.5. 
Table 6. One Way Sample t-Test Showing Psycho-Social Stress as a Factor on Health Conditions of Lecturers in the Tertiary Institutions in Imo State.

\begin{tabular}{|c|c|c|c|c|c|c|c|}
\hline & \multicolumn{7}{|c|}{ Test Value $=12.5$} \\
\hline & \multirow[b]{2}{*}{$\mathrm{T}$} & \multirow[b]{2}{*}{ Mean } & \multirow[b]{2}{*}{ Df } & \multirow[b]{2}{*}{ Sig. (2-tailed) } & \multirow{2}{*}{$\begin{array}{l}\text { Mean } \\
\text { Difference }\end{array}$} & \multicolumn{2}{|c|}{$\begin{array}{ll}95 \% & \text { Confidence } \\
\text { Interval of the } \\
\text { Difference }\end{array}$} \\
\hline & & & & & & Lower & Upper \\
\hline $\begin{array}{l}\text { Psycho- } \\
\text { social stress }\end{array}$ & 107.570 & 17.00 & 381 & .000 & 4.50262 & 4.4203 & 4.5849 \\
\hline
\end{tabular}

Table 6 shows that the significance of $t$ value is .000 which is less than 0.05 and the mean is 17.00 which is greater than the test value which is 12.5 , therefore we reject the hypothesis indicating that psycho-social stress is a factor on health conditions of lecturers in tertiary institutions in Imo State.

This study revealed psycho-social stress is a factor on the health conditions of lecturers in the tertiary institutions. it also revealed that depression, withdrawal, isolating oneself from others, procrastinating or neglecting responsibilities, loss of sex drive were the extent which psychosocial stress affects the health condition of lecturers in tertiary institutions in Imo State. This result is in line with the findings of Usoro (2018), who studied the Occupational stress and its effect on the job effectiveness and health condition of lecturers in federal universities in Akwa Ibom and Cross River states of Nigeria. The results showed that, workload related stress significantly influence the job effectiveness of lecturers in terms of publication, community service and teaching effectiveness. The analysis results indicated that stress from factors workload, facilities; career development requirements and organizational climate significantly affect the health condition of lecturers.

\section{References}

Ahsan. N., Abdullah. Z., Fie. D.Y.G., \& Alam, S.S. (2009). A study of job stress on job satisfaction among university. European Journal of Social Sciences, 8(1), 121-131

Ali MK, Jaacks LM, Kowalski AJ, Siegel KR, Ezzati M. (2015). Noncommunicable diseases: three decades of global data show a mixture of increases and decreases in mortality rates. Health Aff.; 34(9):1444-55.

Allender S, Wickramasinghe K, Goldacre M, Matthews D, Katulanda P. (2011) Quantifying urbanization as a risk factor for noncommunicable disease. Journal of Urban Health; 88(5):906.

Ekwunife OI, Aguwa CN.(2011) A meta analysis of prevalence rate of hypertension in Nigerian populations. J Public Health Epidemiology; 3(13):604-7.

Isara AR, Okundia $\mathrm{PO}(2015)$. The burden of hypertension and diabetes mellitus in rural communities in southern Nigeria. The Pan African medical journal.;20.

Joseph-Shehu E, Irinoye O, Ajani G. (2016). Relationship between blood pressure, body mass index and health promoting lifestyle practices of women in selected rural communities 
in Osun state Nigeria. Research Journal of Health Sciences. 4 (2):112-23.

Kyriacou, C. (1987). Teacher stress and burnout.: An international review. Educational Research,

Leka, S., A. Griffiths and T. Cox, 2004. Work, organisation and stress. Nothingham: UK World Health Organisation.

Mahmood, A., Nudrat, Q. \& Zahoor, F. (2013). Impact of age and level of experience on occupational stress of academic managers at higher educational level. Mediterranean Journal of Social Sciences, 4 (1): 535-541.

Oboegbulem, A. \& Onwurah, C. (2011). Organisation and Management of Education. A Nigerian perspective. Nsukka-Enugu: Great AP Express publishers Ltd.

Reddy, G.L. \& Anuradha, R.V. (2013). Occupational stress of higher secondary teachers working in Velcore. District International Journal of Educational Planning and Administration, 3(1), 4-24.

Slyers, S. (2011). Stress and stressor. The way forward. Lagos: Lola publishers.

Tahir, A.Q. (2011) Effectiveness of Teaching Stress on Academic Performance of College Teachers in Pakistan. International Journal of Humanities and Social Science. 1(3), 123-129.

Uko, E. (2012). The role of emotion control and emotion ruination in stress management training. Kaduna: Shemac publishers

Usoro, A. A.; Etuk, G. R..(2018) Workload Related Stress and Job Effectiveness of University Lecturers in Cross River and Akwa Ibom States, Nigeria. Asian Journal of Social Sciences and Management Studies, 3(1). 34-41. Available at: <http:// www. asianonlinejournals.com/index. 